\title{
Alcoholic liver disease and risk of cholangiocarcinoma: a systematic review and meta-analysis
}

This article was published in the following Dove Press journal:

OncoTargets and Therapy

\author{
Jianping $X$ iong ${ }^{1, *}$ \\ ZiJun Yin ${ }^{2, *}$ \\ Weiyu $\mathrm{Xu}^{1, *}$ \\ Zheng Shen ${ }^{3}$ \\ Ye $\mathrm{Li}^{\prime}$ \\ Xin $\mathrm{Lu}^{\prime}$
}

'Department of Surgery, Peking Union Medical College Hospital, Chinese Academy of Medical Sciences and Peking Union Medical College (CAMS \& PUMC), Beijing 100730 , China; ${ }^{2}$ Department of Oncology, The First Affiliated Hospital, Jinan University, Guangzhou 510630, China; ${ }^{3}$ Department of Orthopaedics, Anhui No. 2 Provincial People's Hospital, Hefei 23004I, China

*These authors contributed equally to this work
Correspondence: Ye Li; Xin Lu Department of Surgery, Peking Union Medical College Hospital, Chinese Academy of Medical Sciences and Peking Union Medical College (CAMS \& PUMC), Beijing 100730, China

Tel +861069156042

Fax +86106915 6043

Email liye@pumch.cn; luxinln@163.com
Background: With the purpose of elevating the risk of cholangiocarcinoma (CCA), alcoholic liver disease (ALD) was shown. Nonetheless, the findings were controversial. Herein, a metaanalysis and a systematic review were conducted to study the relation as mentioned above.

Methods: This study searched PubMed, EMBASE, and SI Web of Science carefully for the related studies published prior to March 2018, followed by the random-effects model to calculate the values of pooled risk ratio with $95 \%$ CIs. In addition, the analyses of sensitivity and subgroup were carried out to further confirm the stability of the outcomes.

Results: Seven articles, consisting of 413,483 healthy controls and 8,962 CCA patients, were included in this meta-analysis. When compared with normal controls, patients with ALD had an enhanced 3.92-fold CCA risk, with studies being heterogeneous (95\% CI $=1.96-5.07$; $\mathrm{OR}=3.92 ; \mathrm{I}^{2}=70.2 \%$ ). However, subgroup analysis showed that ALD had the enhanced risk of intrahepatic cholangiocarcinoma (ICC), instead of extrahepatic cholangiocarcinoma (ECC) (ICC: 95\% CI =3.06-5.92, OR =4.49; ECC: 95\% CI =0.90-3.35, OR=2.12). Additionally, when the analysis was stratified by the geographic area, positive association was observed only in western countries rather than eastern countries (western nations: $95 \% \mathrm{CI}=3.34-6.96, \mathrm{OR}=5.15$; eastern nations: $95 \% \mathrm{CI}=0.38-3.91$, $\mathrm{OR}=2.14$ ). And no essential bias was published.

Conclusion: ALD was greatly associated with the enhanced risk of CCA by 3.92-fold, especially in the ICC.

Keywords: alcoholic liver disease, cholangiocarcinoma, biliary tract neoplasms, meta-analysis

\section{Introduction}

Cholangiocarcinoma (CCA), as a kind of malignancy from the bile duct epithelium, ${ }^{1}$ was first described by Durand-Fardel in 1840. Regarding incidence, CCA is the second among all the primary hepatocellular carcinoma (HCC), taking up 3\% of all the gastrointestinal neoplasms $\mathrm{s}^{2,3}$ and $10 \%-25 \%$ of all the malignant HCCs. Besides, the CCA incidence has been growing recently. And there exist some differences about the epidemiological features between intrahepatic cholangiocarcinoma (ICC) and extrahepatic cholangiocarcinoma (ECC). More specifically, there has been an enhanced ICC incidence, whereas there has been a reduced incidence of ECC in related nations, for instance, the USA and the UK. ${ }^{4}$ The age-adjusted incidence ratio of ICC in the USA has increased by $165 \%$ in the past 20 years while the ratio of ECC has reduced by $14 \% .{ }^{5}$ Furthermore, the patients suffering from CCA have an especially poor prognosis. The related survival rates of generally 1, 3, and 5 years have been shown to be $25.0 \%, 9.7 \%$, and $6.8 \%$, respectively, almost without any changes recently. ${ }^{6}$ Nonetheless, the causes of CCA are still not clear. Recently, some research 
studies have shown that liver diseases, like fatty liver disease and hepatitis $\mathrm{B}$ infection, are related to the development of CCA. ${ }^{7,8}$ In a similar way, the progression or development of CCA may be affected by alcoholic liver disease (ALD). Nonetheless, almost no information can be provided about the relationship between the development of CCA and ALD. As the main cause of mortality and morbidity in the world, ALD is the most common etiology of liver disease. ${ }^{9}$ In fact, the ALD burden is the highest among developed nations, where it may occupy around $9.2 \%$ of all the years of life adjusted by disability. ${ }^{10}$ Thus, both meta-analysis and systematic review were conducted in this study by enrolling related studies to gain a more thorough comprehension of the correlation of cirrhosis with the risk of CCA.

\section{Methods}

The current study was conducted conforming to the PRISMA Statement ${ }^{11}$ and the MOOSE guidelines. ${ }^{12}$

\section{Sources of data and strategy of search}

Databases such as Web of Science, EMBASE, and PubMed were searched for related research studies published with the usage of the following keywords: ("chronic liver disease" or "alcoholic liver disease" or "ALD" or "alcoholic fatty liver" or "chronic liver disease" or "steatosis" or "cirrhosis" or "fibrosis") and ("cholangiocarcinoma" or "biliary tract neoplasms" or "biliary tract cancer" or "bile duct cancer"). The publication date and language were not limited.

\section{Inclusion criteria}

Eligible research studies were included if they met the following criteria: study design (case-control or cohort); ALD as the factor of exposure; CCA or bile duct cancer or biliary tract cancer as the outcomes; the values of risk ratio (RR)/ accessible OR with sufficient data or $95 \%$ CIs for calculation. The one with a bigger population was chosen in the case of the same data as reported by two research studies.

\section{Data extraction and quality evaluation}

Data extraction was conducted independently in the included studies, by WX and ZY, following the standard protocol. The following information was extracted from each paper: nation, publication year, name of the first author, design of study (case-control or cohort), number of subjects, confounding variables, follow-up duration, the values of OR/RR with $95 \%$ CIs, and the sources of controls.

Newcastle-Ottawa scale (NOS) ${ }^{13}$ evaluated the quality of the study and the categories of the quality conformed to the scores of each study. The maximum score was 9 points. Specifically, the NOS scores of 7-9, 4-6, and $<4$ showed high-, medium-, and low-quality studies, respectively. ${ }^{14}$ The consensus dealt with all the discrepancies.

\section{Statistical analysis}

The correlation of cirrhosis with the risk of CCA could be determined with the usage of the random-effects model proposed by DerSimonian and Laird. ${ }^{15}$ Besides, the values of OR and $95 \%$ CIs were used to evaluate the correlation of ALD with the risk of CCA.

Heterogeneity between research studies was studied by the statistic of $\mathrm{I}^{2}$, in which high, medium, and low heterogeneity meant $75 \%, 50 \%$, and $25 \%$, respectively. ${ }^{16}$ In the case of $P$-value $<0.1$, definite heterogeneity was taken into consideration. Meta-regression was used to study the exact heterogeneity degree of the research results with the year of publication (before 2010 vs 2010 and thereafter), number of cases (500 vs 500), geographical region (eastern vs western), and confounders adjusted for (cholangitis, hepatitis infection, and gallstones).

The analysis of subgroup was carried out based on the tumor subtype, geographic regions, and whether cholangitis, gallstones, and hepatitis infection were adjusted. Sensitivity analysis was carried out to evaluate the study effect on the concluded estimation by excluding one research in one turn sequentially. Sensitivity analyses were conducted by changing the pooling model (fixed-effects model or randomeffects model). ${ }^{17}$ Funnel plots and Begg's ${ }^{18}$ and Egger's ${ }^{19}$ tests were employed to assess the publication bias, where a $P$-value $<0.05$ or funnel plot asymmetry was indicative of the bias. ${ }^{20}$

STATA version 12.0 (Stata) was applied in the statistical analysis.

\section{Results}

\section{Selection and features of the research}

Figure 1 shows the process of selection. About 9,275 papers were obtained via the initial search, where 3,027 were duplicates. According to the abstract and title, an extra 6,159 research studies were excluded. Fourteen research studies were eliminated for failure in meeting the inclusion criteria after thorough measurement of the full texts: insufficient statistics were identified in seven studies; four studies did not provide OR, or RR for CCA; and no access of OR, or RR for CCA or inadequate data for calculation of these variables in three studies. Thereby, seven observed studies were finally enrolled in this meta-analysis. ${ }^{21-27}$ 


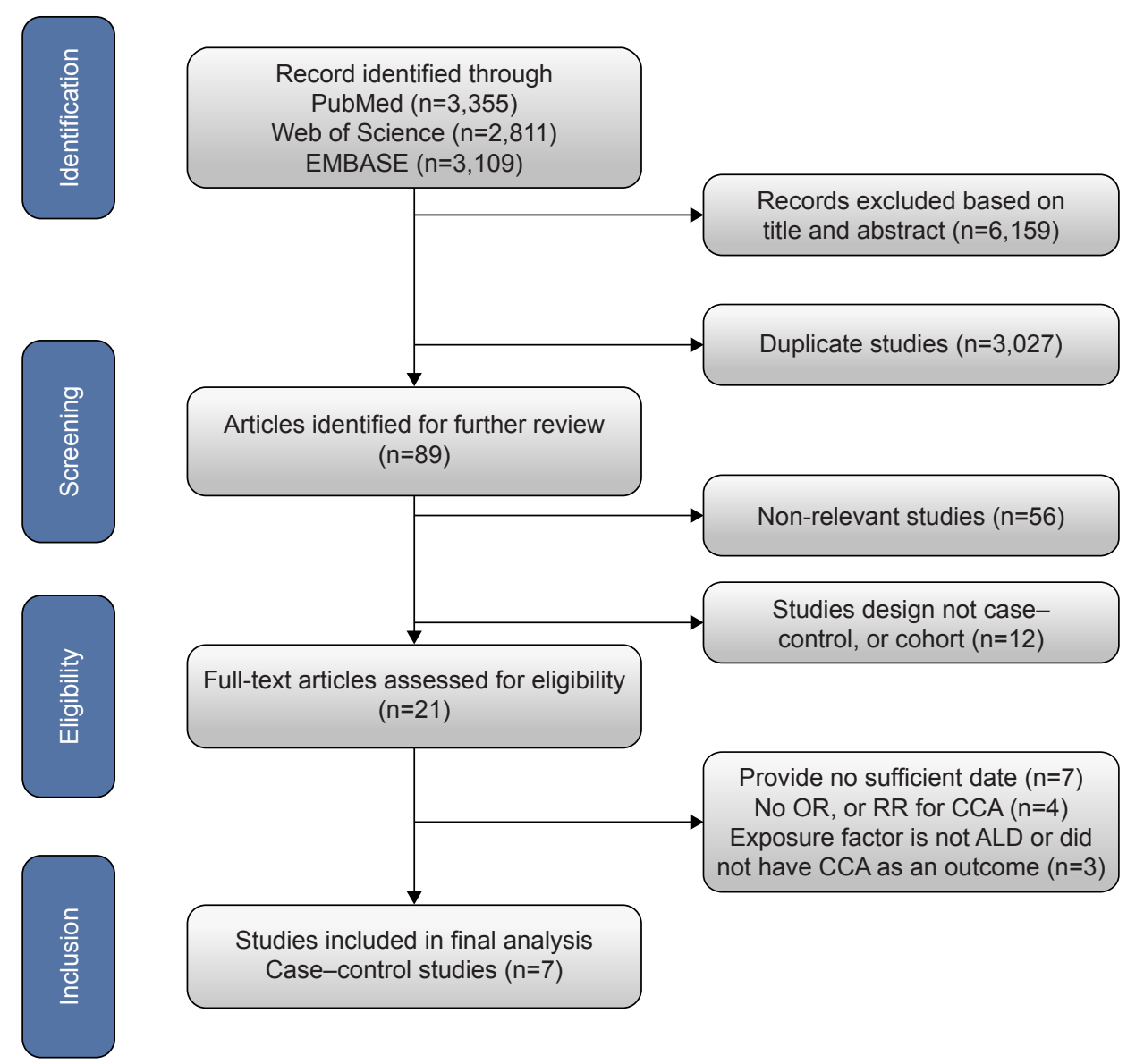

Figure I The process of selecting studies for the meta-analysis.

Abbreviations: ALD, alcoholic liver disease; CCA, cholangiocarcinoma; RR, risk ratio.

Table 1 shows the major features of the research studies in the meta-analysis. ${ }^{21-27}$ The research studies were carried out in the following nations: one in China, Taiwan, and Korea, respectively, and four in the USA. The design of case-control was included in all the research studies. A total of 413,483 healthy controls and 8,962 subjects were chosen to investigate the role of ALD in the risk of CCA in the meta-analysis from 1978 to 2013. As presented in Table 2, the NOS scores of all the chosen studies ranged from 5 to 9 ; two of them had medium quality and five had high quality.

\section{General results}

Seven research studies that were case-control were integrated to examine the relation of ALD with the risk of CCA. As a result, it was found that the patients suffering from ALD had an enhanced related CCA risk in five studies. On the other hand, there was no important relation of ALD with the risk of CCA in only two studies. The pooled analysis showed a close relationship between CCA and ALD. To be more specific, as presented in Figure 2, the risk of CCA was greatly enhanced by ALD (95\% CI: 1.96-5.07; OR =3.92), with studies being significantly heterogeneous $\left(\mathrm{I}^{2}=70.2 \%\right.$; $P=0.003$ ) (Figure 2).

\section{Analyses of sensitivity and subgroup}

Table 3 shows the results of the sensitivity and subgroup analyses. As presented in Table 3, patients suffering from ALD in western nations were more intended to be burdened with CCA than the patients from the East (western nations: 95\% CI: 3.34-6.96, OR $=5.15$; eastern nations: $95 \% \mathrm{CI}$ : $0.38-3.91$, OR $=2.14$ ) (Table 3 ) in the analysis of stratification by geographic region. In addition, as shown in Table 3 , in the individual analysis of ECC and ICC, the results suggested that ALD had a positive effect on the risk of ICC and neutral effect on the risk of ECC (ICC: 95\% CI: 3.06-5.92, $\mathrm{OR}=4.49$; ECC: $95 \%$ CI: 0.90-3.35, OR =2.12). According to the sensitivity analysis, as shown in Table 3 , the general results of the relationship between CCA and ALD were steady in transforming the pooling model (the random-effects model: 95\% CI: 1.96-5.07; OR $=3.92$; the fixed-effects 


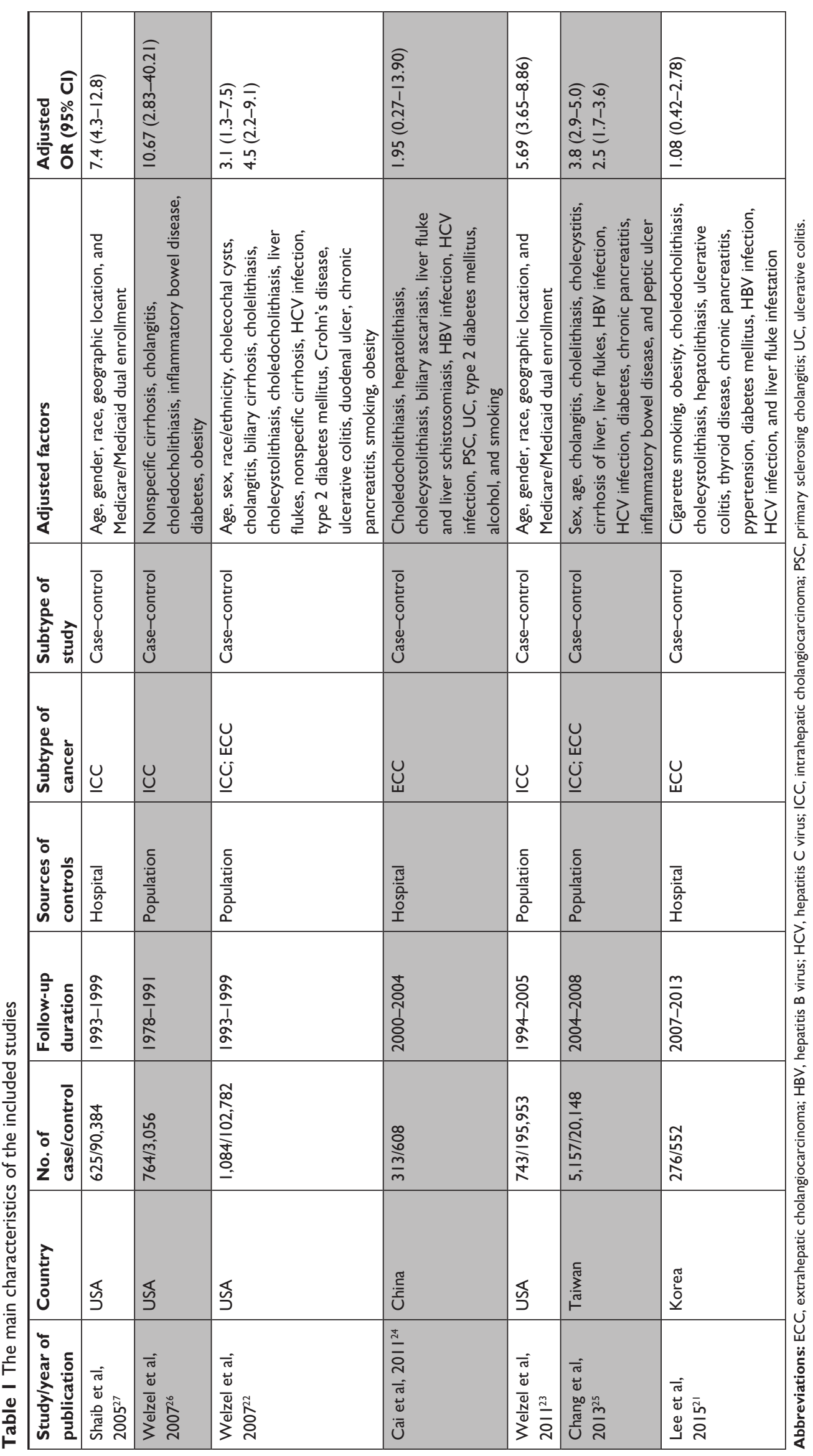




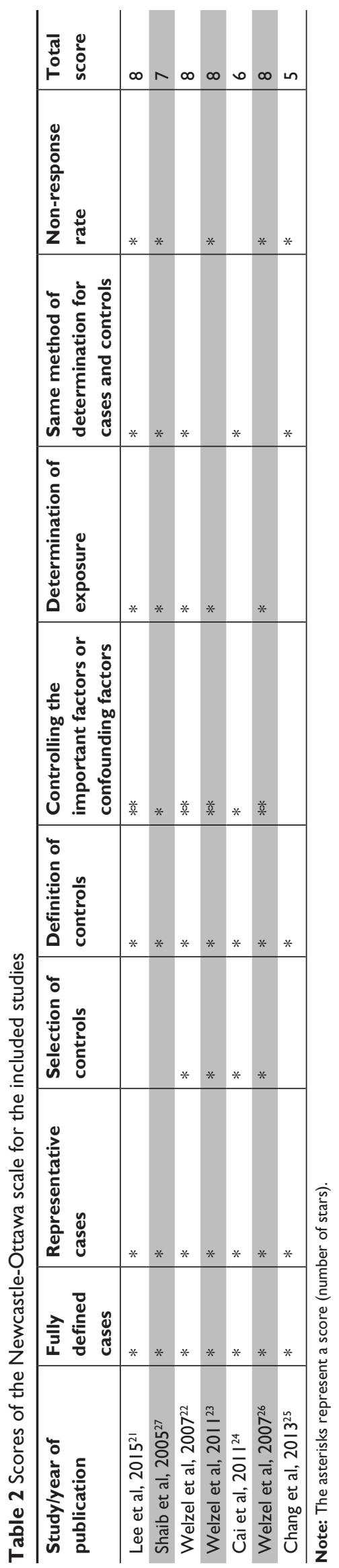

model: 95\% CI: 2.31-3.44, OR =2.87). As shown in Figure 3, the estimation of the pooled risk remained intact by any research in the sequential omission of study one by one to evaluate the stability of results. In addition, the analyses of meta-regression were conducted to study the possible heterogeneous origin. Thus, none of the below could be considered as the heterogeneity source, such as the number of cases ( $P=0.671)$, the year of publication $(P=0.804)$, geographical regions $(P=0.712)$, study quality $(P=0.573)$, gallstones ( $P=0.448)$, cholangitis $(P=0.819)$, and confounders adjusted for smoking status $(P=0.740)$.

\section{Bias of publication}

No substantial asymmetry was shown in the funnel plot. Neither Egger's test $(P=0.741)$ nor Begg's test $(P=0.605)$ showed any significant bias of publication $(P>0.05)$ (Figure 4).

\section{Discussion}

ALD refers to an identified risk factor of $\mathrm{HCC} .{ }^{28}$ Nonetheless, the role of ALD in CCA development as well as the relationship between CCA and ALD was comprehended poorly. Thus, it was shown that ALD was greatly related to CCA, which could greatly enhance the risk of CCA, especially in ICC.

It was shown in the current research that ALD was related to an enhanced risk of CCA. Nonetheless, the accurate cause of CCA was still not clear. First, alcohol could dispose people to CCA development via two mechanisms, including acetaldehyde and cytochrome P450 2E1 (CYP2E1). The induction of CYP2E1, metabolizing ethanol to acetaldehyde, could enhance the reactive production of oxygen species, the damage of DNA, and peroxidation of lipid. Acetaldehyde was generated by the ethanol metabolism and catalyzed by bacterial antidiuretic hormone and mucosal. ${ }^{29}$ Acetaldehyde has been presented to have direct carcinogenic and mutagenic effects in in vivo and in vitro research studies. ${ }^{30}$ Second, cholangiocarcinogenesis might be promoted by the consumption of alcohol via chronic inflammation that led to enhanced oxidative stress. ${ }^{31}$

\section{Strengths}

There were some advantages in this research. First, this is the most comprehensive research that enrolled a large sample size $(8,962 \mathrm{CCA}$ patients in four nations) to investigate the possible role of ALD on the risk of CCA. The findings might offer valid information for the researchers of CCA and might be helpful to clinicians with the goal of establishing methods to prevent CCA development. In the second place, the analyses of sensitivity and subgroup were carried out to 


\begin{tabular}{|c|}
\hline Study ID \\
\hline Lee 2015 \\
\hline Welzel 2007 \\
\hline Welzel 2011 \\
\hline Cai 2011 \\
\hline Chang 2013 \\
\hline Shaib 2005 \\
\hline Welzel 2006 \\
\hline Overall $\left(I^{2}=70.2 \%, P=0.003\right)$ \\
\hline
\end{tabular}

Figure 2 Forest plot showing the relationship between alcoholic liver disease and the risk of cholangiocarcinoma.

Notes: Points represent the risk estimates for each individual study. Horizontal lines represent $95 \% \mathrm{Cls}$, and diamonds represent the summary risk estimates with $95 \% \mathrm{Cls}$. Weights are from random-effects analysis.

Abbreviation: ES, effect size.

point out the factors that affected the risk of CCA. In addition, the comprehensive searches of Web of Science, PubMed, and EMBASE were carried out to extract the studies to investigate the factors that influenced the risk of CCA, which further proved the findings. Last but not least, the quality of the studies, such as the bias in the results, was evaluated in the meta-analysis. The random- and fixed-effects models were used to conclude the ALD effects on the CCA risk,

Table 3 Subgroup and sensitivity analyses of the effect of alcoholic liver disease and the risk of cholangiocarcinoma

\begin{tabular}{|c|c|c|c|c|}
\hline Subgroup & No. of studies & OR $(95 \% \mathrm{Cl})$ & $I^{2}$ value (\%) & $P$-value \\
\hline All studies & 7 & $3.52(1.96-5.07)$ & 70.2 & 0.003 \\
\hline $\begin{array}{l}\text { Subtype of cancer } \\
\text { ECC } \\
\text { ICC }\end{array}$ & $\begin{array}{l}4 \\
5 \\
\end{array}$ & $\begin{array}{l}2.12(0.90-3.35) \\
4.49(3.06-5.92)\end{array}$ & $\begin{array}{l}44.5 \\
29.2 \\
\end{array}$ & $\begin{array}{l}0.145 \\
0.240\end{array}$ \\
\hline $\begin{array}{l}\text { Geographic areas } \\
\text { West } \\
\text { East }\end{array}$ & $\begin{array}{l}4 \\
3\end{array}$ & $\begin{array}{l}5.15(3.34-6.96) \\
2.14(0.38-3.91)\end{array}$ & $\begin{array}{l}14.6 \\
75.7\end{array}$ & $\begin{array}{l}0.319 \\
0.016\end{array}$ \\
\hline Adjustment for confounders & & & & \\
\hline $\begin{array}{l}\text { Gallstones } \\
\text { Yes } \\
\text { No }\end{array}$ & $\begin{array}{l}5 \\
2\end{array}$ & $\begin{array}{l}2.52(1.09-3.96) \\
6.13(3.97-8.30)\end{array}$ & $\begin{array}{l}61.2 \\
0\end{array}$ & $\begin{array}{l}0.035 \\
0.497\end{array}$ \\
\hline $\begin{array}{l}\text { Hepatitis B/C } \\
\text { Yes } \\
\text { No }\end{array}$ & $\begin{array}{l}4 \\
3 \\
\end{array}$ & $\begin{array}{l}2.48(1.06-3.91) \\
6.20(4.04-8.36) \\
\end{array}$ & $\begin{array}{l}67.3 \\
0 \\
\end{array}$ & $\begin{array}{l}0.027 \\
0.559 \\
\end{array}$ \\
\hline $\begin{array}{l}\text { Cholangitis } \\
\text { Yes } \\
\text { No }\end{array}$ & $\begin{array}{l}3 \\
4 \\
\end{array}$ & $\begin{array}{l}3.14(2.47-3.82) \\
4.19(0.70-7.68)\end{array}$ & $\begin{array}{l}0 \\
77.5\end{array}$ & $\begin{array}{l}0.603 \\
0.001\end{array}$ \\
\hline Sensitivity analyses & & & & \\
\hline $\begin{array}{l}\text { Fixed-effects vs random-effects model method } \\
\text { Fixed-effects model } \\
\text { Random-effects model }\end{array}$ & $\begin{array}{l}7 \\
7\end{array}$ & $\begin{array}{l}2.87(2.31-3.44) \\
3.52(1.96-5.07)\end{array}$ & $\begin{array}{l}70.2 \\
70.2\end{array}$ & $\begin{array}{l}0.003 \\
0.003\end{array}$ \\
\hline
\end{tabular}

Note: $P$-value is for heterogeneity.

Abbreviations: ECC, extrahepatic cholangiocarcinoma; ICC, intrahepatic cholangiocarcinoma. 


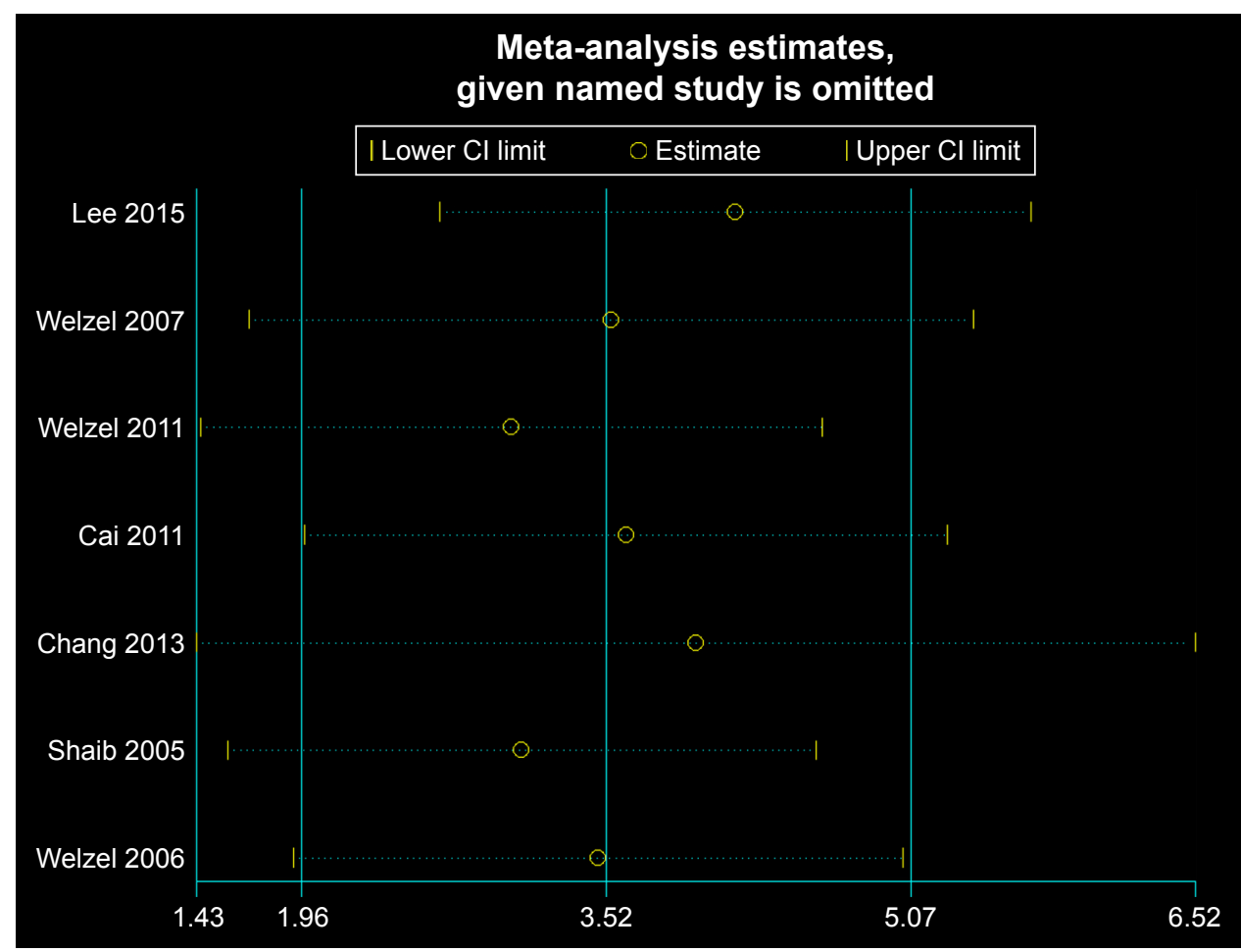

Figure 3 Sensitivity analysis of the association between alcoholic liver disease and the risk of cholangiocarcinoma.

and the results from the two model types were compared accordingly.

\section{Limitations}

Nonetheless, there were certain restrictions in the research. First, all the research studies enrolled were case-control design, thus resulting in the recall generation and the biases of selection. In addition, the diagnostic bias might influence the results of the current research. ALD patients tended to

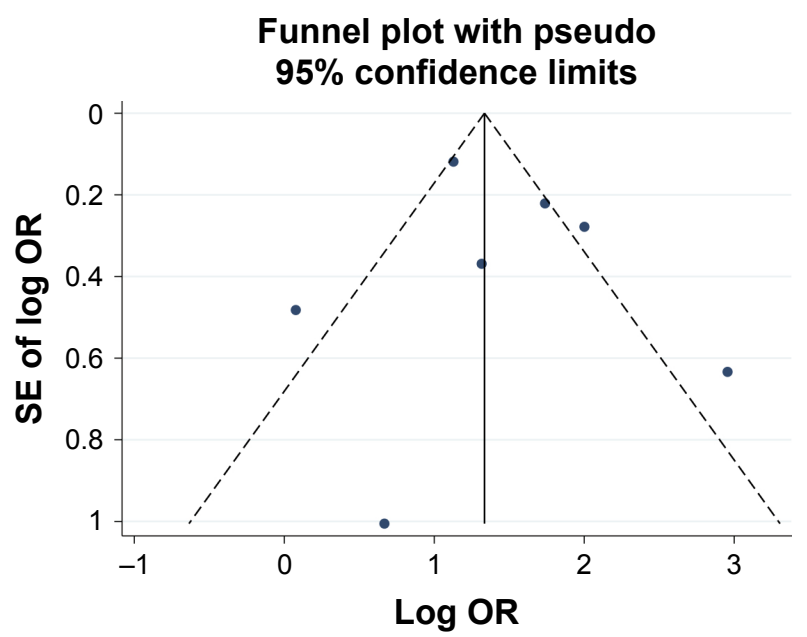

Figure 4 Funnel plot of studies included in the meta-analysis of the relationship between alcoholic liver disease and the risk of cholangiocarcinoma. Abbreviation: SE, standard error. have more frequent physical examination, which may lead to more diagnoses than controls. Second, the data about the antiviral treatment in the patients infected with $\mathrm{HCV}$ and HBV were unavailable, which may influence the risk of CCA development. Third, confounders might affect the relation between the risk of CCA and ALD. This study did not adjust the confounders, like particular dietary factors or cholangitis even though the adjustments for some confounders that might have influenced the outcomes were conducted. Fourth, a meta-analysis on the effects of different types of ALD was not performed due to the limited number of included studies in the analysis. Moreover, many of the studies included in the meta-analysis did not indicate the type of ALD in the article. It may be considered another potential limitation of this study. Among the seven studies included, three studies reported results on cirrhosis, ${ }^{3-5}$ with two studies showing a significantly increased the risk of CCA. ${ }^{3,4}$ And previous studies indicated that alcohol use was the major risk factor for ICC, ${ }^{6}$ but not ECC. ${ }^{7}$ In the metaanalysis, the results obtained by Lee et al suggested that alcohol did not obviously change the risk of CCA. ${ }^{21}$ Last but not least, the number of studies on CCA was very less. Thereby, the assessment of heterogeneity and the pooled effects might be imprecise, and the researchers' publication bias could not be sufficiently evaluated. To solve the problem, some analyses of subgroup and sensitivity were 
conducted even though the source of heterogeneity was not always ascertained.

\section{Conclusion}

It was demonstrated that the risk of CCA was enhanced by 3.92-fold by ALD. Furthermore, patients suffering from ALD tended to further develop ICC, instead of ECC. And more basic and prospective studies were carried out to further confirm the relation of ALD with the risk of CCA and to study the potential mechanisms.

\section{Acknowledgments}

The study was funded by the Capital Special Research Project for Clinical Application (Z151100004015170).

\section{Author contributions}

All authors contributed to data analysis, drafting and revising the article, gave final approval of the version to be published, and agree to be accountable for all aspects of the work.

\section{Disclosure}

The authors report no conflicts of interest in this work.

\section{References}

1. Olnes MJ, Erlich R. A review and update on cholangiocarcinoma. Oncology. 2004;66(3):167-179.

2. Vauthey JN, Blumgart LH. Recent advances in the management of cholangiocarcinomas. Semin Liver Dis. 1994;14(2):109-114.

3. Shaib Y, El-Serag HB. The epidemiology of cholangiocarcinoma. Semin Liver Dis. 2004;24(2):115-125.

4. Taylor-Robinson SD, Toledano MB, Arora S, et al. Increase in mortality rates from intrahepatic cholangiocarcinoma in England and Wales 1968-1998. Gut. 2001;48(6):816-820.

5. Shaib YH, Davila JA, Mcglynn K, El-Serag HB. Rising incidence of intrahepatic cholangiocarcinoma in the United States: a true increase? J Hepatol. 2004;40(3):472-477.

6. Lepage C, Cottet V, Chauvenet M, et al. Trends in the incidence and management of biliary tract cancer: a French population-based study. J Hepatol. 2011;54(2):306-310.

7. Fwu CW, Chien YC, You SL, et al. Hepatitis B virus infection and risk of intrahepatic cholangiocarcinoma and non-Hodgkin lymphoma: a cohort study of parous women in Taiwan. Hepatology. 2011;53(4): $1217-1225$

8. Wongjarupong N, Assavapongpaiboon B, Susantitaphong P, et al. Non-alcoholic fatty liver disease as a risk factor for cholangiocarcinoma: a systematic review and meta-analysis. BMC Gastroenterol. 2017; 17(1):149.

9. Mathurin P, Bataller R. Trends in the management and burden of alcoholic liver disease. J Hepatol. 2015;62(1 Suppl):S38-S46.

10. Liangpunsakul S, Haber P, Mccaughan GW. Alcoholic Liver Disease in Asia, Europe, and North America. Gastroenterology. 2016;150(8): 1786-1797.

11. Moher D, Liberati A, Tetzlaff J, Altman DG; PRISMA Group. Preferred reporting items for systematic reviews and meta-analyses: the PRISMA Statement. Open Med. 2009;3(3):e123-e130.
12. Stroup DF, Berlin JA, Morton SC, et al. Meta-analysis of observational studies in epidemiology: a proposal for reporting. Meta-analysis Of Observational Studies in Epidemiology (MOOSE) group. JAMA. 2000; 283(15):2008-2012.

13. Stang A. Critical evaluation of the Newcastle-Ottawa scale for the assessment of the quality of nonrandomized studies in meta-analyses. Eur J Epidemiol. 2010;25(9):603-605.

14. Zhang YP, Li WQ, Sun YL, Zhu RT, Wang WJ. Systematic review with meta-analysis: coffee consumption and the risk of gallstone disease. Aliment Pharmacol Ther. 2015;42(6):637-648.

15. Dersimonian R, Laird N. Meta-analysis in clinical trials. Control Clin Trials. 1986;7(3):177-188.

16. Higgins JP, Thompson SG. Quantifying heterogeneity in a metaanalysis. Stat Med. 2002;21(11):1539-1558.

17. Xiong J, Lin J, Wang A, et al. Tea consumption and the risk of biliary tract cancer: a systematic review and dose-response meta-analysis of observational studies. Oncotarget. 2017;8(24):39649-39657.

18. Begg CB, Mazumdar M. Operating characteristics of a rank correlation test for publication bias. Biometrics. 1994;50(4):1088-1101.

19. Egger M, Smith GD, Schneider M, Minder C. Bias in meta-analysis detected by a simple, graphical test. BMJ. 1997;315(7):629-634.

20. Stuck AE, Rubenstein LZ, Wieland D. Bias in meta-analysis detected by a simple, graphical test. Asymmetry detected in funnel plot was probably due to true heterogeneity. BMJ. 1998;316(7129):469-471.

21. Lee BS, Park EC, Park SW, Nam CM, Roh J. Hepatitis B virus infection, diabetes mellitus, and their synergism for cholangiocarcinoma development: a case-control study in Korea. World J Gastroenterol. 2015; 21(2):502-510.

22. Welzel TM, Graubard BI, El-Serag HB, et al. Risk factors for intrahepatic and extrahepatic cholangiocarcinoma in the United States: a population-based case-control study. Clin Gastroenterol Hepatol. 2007;5(10):1221-1228.

23. Welzel TM, Graubard BI, Zeuzem S, El-Serag HB, Davila JA, Mcglynn KA. Metabolic syndrome increases the risk of primary liver cancer in the United States: a study in the SEER-Medicare database. Hepatology. 2011;54(2):463-471.

24. Cai WK, Sima H, Chen BD, Yang GS. Risk factors for hilar cholangiocarcinoma: a case-control study in China. World J Gastroenterol. 2011; 17(2):249-253.

25. Chang JS, Tsai CR, Chen LT. Medical risk factors associated with cholangiocarcinoma in Taiwan: a population-based case-control study. PLoS One. 2013;8(7):e69981.

26. Welzel TM, Mellemkjaer L, Gloria G, et al. Risk factors for intrahepatic cholangiocarcinoma in a low-risk population: a nationwide case-control study. Int J Cancer. 2007;120(3):638-641.

27. Shaib YH, El-Serag HB, Davila JA, Morgan R, Mcglynn KA. Risk factors of intrahepatic cholangiocarcinoma in the United States: a casecontrol study. Gastroenterology. 2005;128(3):620-626.

28. Tokushige K, Hyogo H, Nakajima T, et al. Hepatocellular carcinoma in Japanese patients with nonalcoholic fatty liver disease and alcoholic liver disease: multicenter survey. $J$ Gastroenterol. 2016;51(6):586-596.

29. Petrick JL, Campbell PT, Koshiol J, et al. Tobacco, alcohol use and risk of hepatocellular carcinoma and intrahepatic cholangiocarcinoma: The Liver Cancer Pooling Project. Br J Cancer. 2018;118(7):1005-1012.

30. Paget V, Lechevrel M, Sichel F. Acetaldehyde-induced mutational pattern in the tumour suppressor gene TP53 analysed by use of a functional assay, the FASAY (functional analysis of separated alleles in yeast). Mutat Res. 2008;652(1):12-19.

31. Seitz HK, Stickel F. Risk factors and mechanisms of hepatocarcinogenesis with special emphasis on alcohol and oxidative stress. Biol Chem. 2006;387(4):349-360. 
OncoTargets and Therapy

\section{Publish your work in this journal}

OncoTargets and Therapy is an international, peer-reviewed, open access journal focusing on the pathological basis of all cancers, potential targets for therapy and treatment protocols employed to improve the management of cancer patients. The journal also focuses on the impact of management programs and new therapeutic agents and protocols on

patient perspectives such as quality of life, adherence and satisfaction. The manuscript management system is completely online and includes a very quick and fair peer-review system, which is all easy to use. Visit http://www.dovepress.com/testimonials.php to read real quotes from published authors.

Submit your manuscript here: http://www.dovepress.com/oncotargets-and-therapy-journal 